\title{
A Dense Manganese Porphyrin-Nanobar Random Arrays: Direct and Electrocatalytic Oxidation of Ascorbic Acid in the Presence of Dopamine and Uric Acid
}

\author{
Mojtaba Shamsipur ${ }^{1 *}$, Hashem Sharghi ${ }^{2}$ and Afshin Pashabadi ${ }^{*}$ \\ ${ }^{1}$ Department of Chemistry, Razi University, Iran \\ ${ }^{2}$ Department of Chemistry, Faculty of Science, Shiraz University, Iran
}

\begin{abstract}
An array of micro/nanoelectrodes offers most of the advantages of single micro/nanoelectrodes, but with the added benefit of a higher total current output and increasing sensitivity. This work reports the analytical performance of a gold electrode modified with a Mn(III) porphyrin nanobar-film (NBMn$\mathrm{PPh}$ ) employed for the sensitive determination of Ascorbic Acid (AA) at $\mathrm{pH}=7.4$ in the presence of always coexistence interferences Dopamine (DA) and Uric Acid (UA). The electropolymerized $\mathrm{PPh}$ film demonstrate a dense random array of nanobars with diameter of $50-70 \mathrm{~nm}$ at the surface of gold electrode. Two anodic peaks was appeared at 260 and $380 \mathrm{mV}$ due to direct and catalytic oxidation of $A A$, respectively, that the catalytic peak being more sensitive than the first one. The good sensitivity of sensor can be concluded by physical reasons other than changes in the electrode kinetic. The great number of nanoparticles results in induces thin-layer cell effect at the interface of electrode/electrolyte. The hydrodynamic amperometry at rotating modified-electrode was used for the determination of tryptophan in the range of $0.2-0.8 \mu \mathrm{M}$. The detection limit was found to be 8.4 $\mathrm{nM}$ based on $\mathrm{S} / \mathrm{N}=3$.
\end{abstract}

Keywords

Random arrays microelectrodes, Electrocatalytic oxidation, Ascorbic acid, Porphyrin

\section{Introduction}

Microelectrode arrays demonstrated an attractive behavior relate to macroelectrodes, as they can produce voltammetric responses of similar magnitude to their macro counterparts, but with a considerably less capacitive/background current. Hence, they have found an increasing use in electroanalytical sensing devices. Recently, some researches were focused on designing new types of sensing-arrays that employed micro/nanoelectrodes in both regular and random distributions [1,2]. These structures, due to their many advantageous properties, including low background charging currents, large current density related to convergent diffusion and importantly small diffu- sion path between each adjacent microelectrode elements, are now routinely used in analytical applications [3]. The behavior of microarrays arrays strongly depends on the degree to which each microelectrode element in the array is diffusionally independent from the other adjacent elements. It is clear this in turn depends on both the separation of each microelectrode in the array relative to the diameter of the individual microelectrodes and also on the timescale of the voltammetric experiment [4-6]. Therefore, the useful properties of a single microelectrode can often be improved by the use of either an ordered or a random array of microelectrodes. There are a variety of literature methods such as electrochemical or electroless deposition of nanoparticles onto a suitable electrode substrate for fabrication of arrays

*Corresponding author: Mojtaba Shamsipur and Afshin Pashabadi, Department of Chemistry, Razi University, Kermanshah, Iran, E-mail: mshamsipur@yahoo.com; afshin.pashabadi@gmail.com

Received: September 09, 2017: Accepted: December 28, 2017: Published: December 30, 2017

Copyright: ( 2017 Shamsipur M, et al. This is an open-access article distributed under the terms of the Creative Commons Attribution License, which permits unrestricted use, distribution, and reproduction in any medium, provided the original author and source are credited. 
of micro/nanoelectrodes on electrode surfaces $[3,7,8]$. It is noteworthy that many random arrays of nanoparticles on the electrode surface, so that the array rarely, if not ever, is diffusionally independent in most practical experimental timescales.

Ascorbic Acid (AA, vitamin C), which is present in both the animal and plant kingdoms, is an essential nutrient for humans and plays a critical role in biological metabolism. It helps in cell development, the healing of injuries and burns and in the synthesis of collagen, blood vessels, cartilage, bones and tendons $[9,10]$. Moreover, AA is of great importance for therapeutic purposes including its use for the prevention and treatment of the common cold, mental illness, infertility, cancer and AIDS [11]. Thus, the development of a simple, rapid, sensitive, selective and reliable method for the determination of AA is still desirable for diagnostic and food safety applications.

Several methods such as electrophoresis [12], fluorescence [13], chemiluminescence [14], liquid chromatography [15] and electrochemical methods [16-22] have been reported for the determination of AA. Among these, the electrochemical methods are considered as the most potential approaches because of their high sensitivity, simplicity and low cost. However, the electrochemical oxidation of AA and co-existing electroactive components such as Uric Acid (UA) and Dopamine (DA) results in highly overlapping peaks, leading to poor reproducibility and low selectivity. Thus, the selective detection of AA in the presence of the other two species or their simultaneous determination has been a major goal of much research [18-24].

In this study, we synthesized random arrays of manganese-nanobar film at the surface of an Au electrode. In recent years, our research groups have been successfully report some application of nanomaterials in electrochemical sensors and biosensors [25-28]. The prepared electrode showed a distinct behavior at different AA centration ranges in a way that provides two paths for oxidation of AA through a direct path and an electrocatalysis path. The prepared nanobars possess a diameter of 50-70 $\mathrm{nm}$ and a length $120-170 \mathrm{~nm}$ in a closest arrangement. The modified electrode found to have a strong electrocatalytic activity toward AA in the presence of DA and UA.

\section{Experimental}

\section{Reagents}

Ascorbic Acid and dopamine were purchased from Sigma-Aldrich. Uric acid was prepared from merck. All other chemicals were of analytical grade from Merck and used as received. Before starting each set of experiments, the stock solutions of AA were prepared in $0.050 \mathrm{M}$ phosphate buffer of $\mathrm{pH} 7.4$, covered with aluminum foil, and stored in ice bath. During experiments the required solutions were prepared by serial-dilution of the stock solutions. Double-distilled water was used throughout. Phosphate buffer solutions were prepared by mixing appropriate amounts of dipotassium hydrogen phosphate and potassium dihydrogen phosphate (both provided by Sigma-Aldrich), to obtain the desired $\mathrm{pH}$ value 7.4. The standard solutions of other compounds (each $10.0 \mathrm{mM}$ ) were prepared by dissolving of appropriate amount of each in double distilled water.

\section{Apparatus}

Electrochemical measurements were carried out on a $\mu$-Auto lab type III (Eco Chemie B.V.A) computer-controlled potentiostat and run with the GPES software. The electrochemical cell was assembled with a saturated $\mathrm{Ag} / \mathrm{AgCl}$ reference electrode, a $\mathrm{Pt}$ wire auxiliary electrode and the prepared working electrode. The $\mathrm{pH}$ measurements were performed using a $781 \mathrm{pH} /$ ion meter equipped with a combined glass electrode. The Scanning Electron Microscopy (SEM) studies were conducted on a Philips XL 30 instrument operating at $20 \mathrm{keV}$. All experiments were carried out at ambient temperature (20 $\pm 2{ }^{\circ} \mathrm{C}$ ). The constructed working-electrodes were kept in air when not in use. The electrochemical characteristics of the modified electrode were measured using cyclic voltammetry and Faradaic impedance spectroscopy. The electrochemical cell consisted of a three-electrode system, in which an Au electrode with an effective surface of $0.07 \mathrm{~cm}^{2}$ was used as working electrode. The Z-view modeling program was used.

\section{Preparation of serum samples}

Human serum samples were collected from the volunteers by a pathology laboratory in Kermanshah city and were stored frozen until measurements. To $3.0 \mathrm{ml}$ of serum sample $5.0 \mathrm{ml}$ methanol was added. After vortexing of the serum sample for $5 \mathrm{~min}$, the precipitated proteins were separated by centrifugation for $5 \mathrm{~min}$ at 5500 $\mathrm{rpm}$. The clear supernatant layer was filtered through $0.45 \mu \mathrm{m}$ milli-pore filter to obtain protein-free human serum sample and its volume was adjusted to $25 \mathrm{ml}$ using phosphate buffer $0.05 \mathrm{M}$ to get the optimum $\mathrm{pH}$. The resulting serum sample was then analyzed by the proposed sensor for the AA detection, using the spiked amounts and the standard addition method.

\section{Modification procedure}

After polishing and rinsing in an ultrasonic cleaner, the $\mathrm{Au}$ electrode was placed in a $\mathrm{CH}_{3} \mathrm{CN} / \mathrm{H}_{2} \mathrm{O}(60 / 40 \mathrm{v} / \mathrm{v})$ solution containing $0.1 \mathrm{M} \mathrm{KCl}$ and $8.0 \mathrm{mM}$ manganese(III) porphyrin complex and potential was cycled between -0.2 and $0.8 \mathrm{~V}$ at a scan rate of $40 \mathrm{mVs}^{-1}$ for 35 cycles. The peak currents increase steadily with increasing scan number up to 35 runs, indicating the continuous deposition of manganese complex film at the electrode surface. While, the anod- 

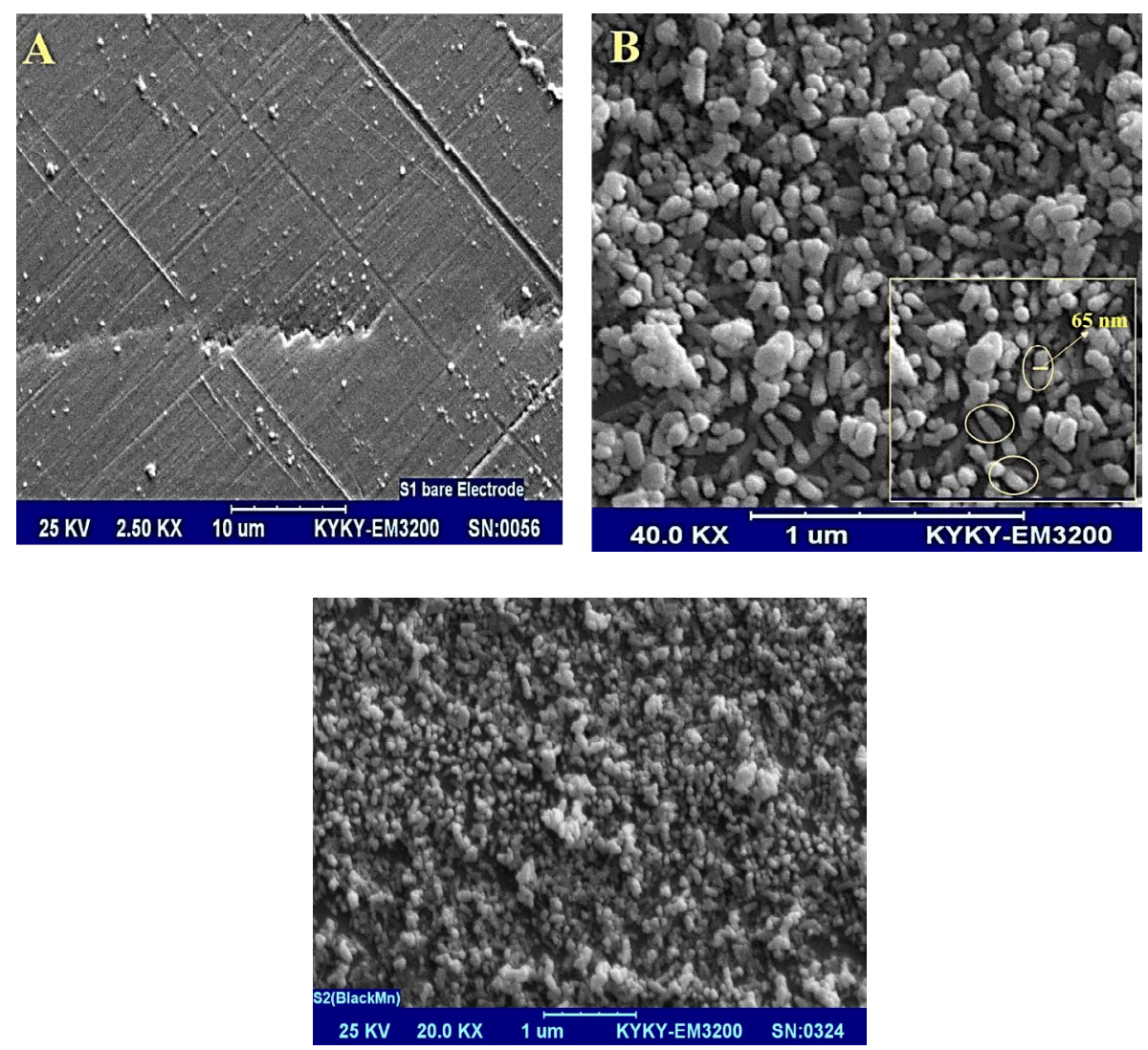

Figure 1: Typical SEM of A) Au bare; B) NBMn-PPh-Au electrode.

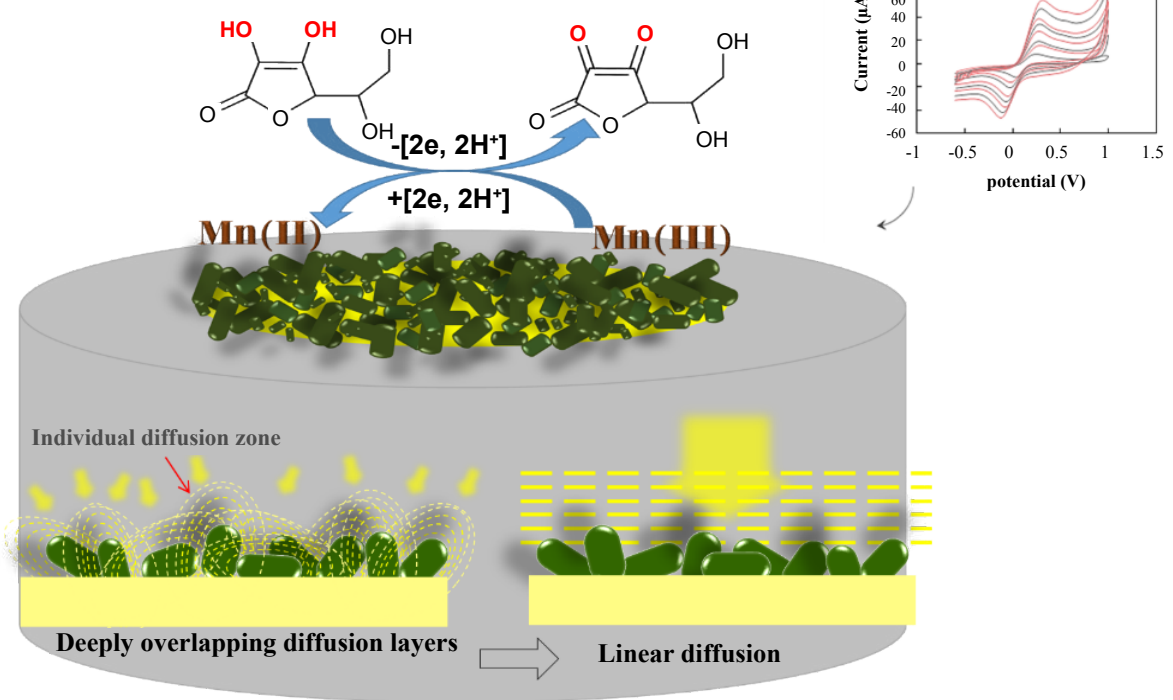

Figure 2: A) The behavior same neighboring electrodes at different voltammetric time scales that their diffusion layers are fully overlapping and diffusion to the electrodes is now planar, not convergent (type IV behavior); B) Cyclic voltammograms for the electrochemical oxidation of $2.5 \mathrm{mM}$ ferrocyanide in $0.1 \mathrm{M} \mathrm{KCl}$ (vs. SCE) using scan rates of 10, 30, 50, 100, 150, 200, $300,400 \mathrm{mVs}^{-1}$ at the NBMn-PPh electrode.

ic and cathodic peak currents did not alter upon further potential cycling. After modification procedure, the electrode was thoroughly rinsed and cycled between -0.3 and $0.7 \mathrm{~V}$ in $50 \mathrm{mM}$ phosphate buffer $\mathrm{pH} 7.0$ until a reproducible cyclic voltammogram was obtained.

\section{Results and Discussion}

\section{SEM study: Polydisperse distribution of diffusion domains}

To investigate the surface structure and morphology of 
the modified electrode, the SEM images of bare Au (Figure $1 \mathrm{~A}$ ), and nanobar modified Au electrode (Figure 1B) were obtained. As is seen, the Randomly Array Nanobar Electrodes (RANBEs), with a diameter of $62 \pm 5 \mathrm{~nm}$ and a length $150 \pm 15 \mathrm{~nm}$ in a closest arrangement, are more adjacent. Meanwhile, some agglomerations can be seen at the surface of the nano-structured electrode. The diffusion to ensembles of microelectrodes has been well described in the literature, using both analytical and simulation techniques [29-31], and the proposed assumptions can also be applied to our case. In this study, because of the close vicinity of individual diffusion zones at RANBEs, the shape of individual nanostructures may not affect the final shape of the deeply overlapped diffusional zones so that the linear diffusion assumption can be correct.

In Figure $2 \mathrm{~A}$ is illustrated the side schematic view of a random array of nanobars on the electrode surface [32]. The small spacing between individual nanoelectrodes and packing of active electrode sites may result in overlapping of diffusion zones and the resultant planar diffusion to RANBEs to improve the signal-to-noise ratio. In order to have a further support for the proposed scheme, the cyclic voltammetric responses $2.5 \mathrm{mM}$ of $\left[\mathrm{Fe}(\mathrm{CN})_{6}\right]^{3-/ 4}$ solution containing $0.1 \mathrm{M} \mathrm{KCl}$ using the RANBEs electrode over a range of scan rates $\left(10-400 \mathrm{mVs}^{-1}\right)$ were recorded (Figure 2B). The shape and magnitude of the voltammetric response are highly dependent on two factors: (i) Size of the individual microelectrodes vs. size of the diffusion zones and (ii) Size of the diffusion zones vs. size of the spacing between each individual microelectrode $[33,34]$. Consequently, the voltammetric results of a microelectrodes array can be assigned to one (or a combination) of the following four categories depending on these two factors. In category 1, the diffusion layer thickness, $\delta$, is small, compared to the size of the microelectrodes, resulting in linear diffusion dominating mass transport. In category $2, \delta$ is larger than the size of microelectrodes but not so large as to cause adjacent diffusion layers to overlap. In category $3, \delta$ is greater than the size of the spacing between each individual microelectrode resulting in the overlap of adjacent diffusion layers, which is often seen as the source of scan rate dependence and peak currents in microelectrode array voltammetry. In category $4, \delta$ far exceeds the size of the separating layer, resulting in complete overlap of individual diffusion zones and a linear concentration profile. Thus, from the diffusion layer thickness, $\delta$, and the distance between neighboring microelectrodes, the category type can be evaluated.

The Einstein equation (1) indicates that the approximate distance, $\delta$, diffused by a species with a diffusion coefficient $\mathrm{D}$ is equal to $[35,36]$ :

$$
\delta=\left[2 \mathrm{D}\left(\frac{\Delta \mathrm{E}}{\theta}\right)\right]^{\frac{1}{2}}
$$

Where $v$ is the scan rate and $\Delta \mathrm{E}$ is the potential range over which electrolysis has occurred. Here, the difference between the electrolysis started potential and the peak potential $\Delta \mathrm{E}$ was about $0.3 \mathrm{~V}$ and the value of $\mathrm{D}$ was taken as $4.9 \times 10^{6} \mathrm{~cm}^{2} \mathrm{~s}^{-1}$, as obtained from chronoamperometric measurements using the modified electrode at different concentrations $\left[\mathrm{Fe}(\mathrm{CN})_{6}\right]^{3-/ 4-}(1-8 \mathrm{mM})$ by Cottrell's equation. Therefore, the $\delta$ values for different scan rates were calculated and the results are shown in Table 1 . The results clearly revealed that the mean spacing between each individual microelectrode (i.e. $\leq 10 \mu \mathrm{m}$ ) was much smaller than the $\delta$ values obtained at all scan rates, which is consistent with the category 4 insisting on complete overlap of individual diffusion zones and a linear concentration profile behavior and the diameter of each microelectrode were obtained from SEM image (Figure 1A). As observed in Table 1 , the obtained values are very larger than the spacing between each individual microelectrode. These characteristics associated with i.e. planer diffusion zones, scan rate dependence, and confirmed the previous statement.

Table 1: Estimated values of the diffusion layer thickness, $d$, at $\triangle \mathrm{E} \sim 300 \mathrm{mV}$ vs. SCE for CVs of $5 \mathrm{mM}$ ferrocyanide in $0.1 \mathrm{M} \mathrm{KCl}$ (vs. SCE) using scan rates of 10, 30, 50, 100, 150, 200, 300, $400 \mathrm{mV}^{-1}$ at the NBMn-PPh electrode.

\begin{tabular}{|l|l|l|l|}
\hline Scan rate & $\boldsymbol{\delta}(\boldsymbol{\mu m})$ & Category & $\boldsymbol{\delta}$ to d \\
\hline 10 & 172 & 4 & $\delta>>d$ \\
\hline 30 & 99 & 4 & $\delta>>d$ \\
\hline 50 & 77 & 4 & $\delta>>d$ \\
\hline 100 & 54 & 4 & $\delta>>d$ \\
\hline 150 & 44 & 4 & $\delta>>d$ \\
\hline 200 & 38 & 4 & $\delta>>d$ \\
\hline 300 & 31 & 4 & $\delta>>d$ \\
\hline 400 & 27 & 4 & $\delta>>d$ \\
\hline
\end{tabular}

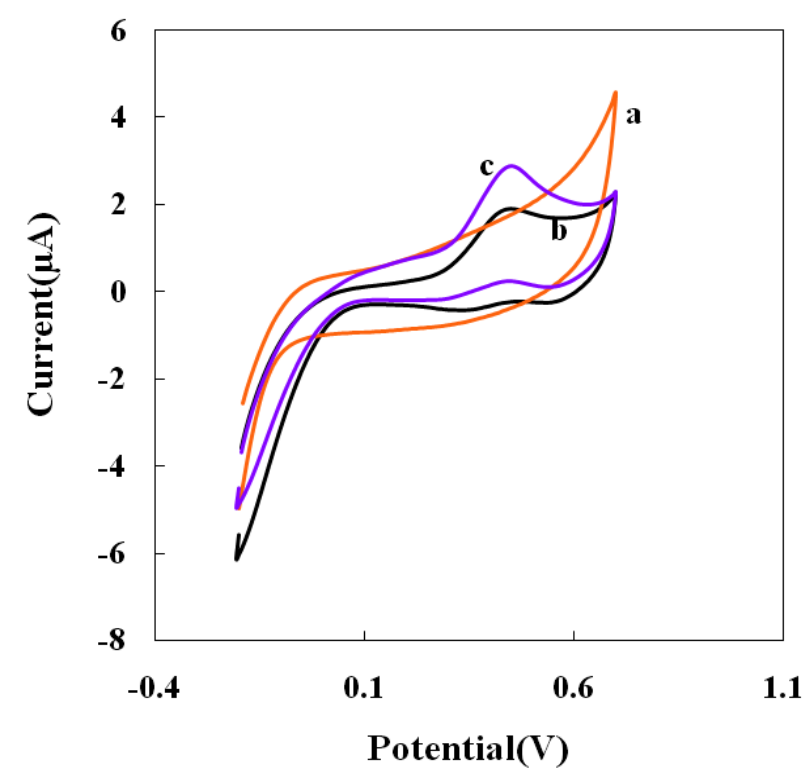

Figure 3: Cyclic voltammograms Au electrode (curve a) and NBMn-PPh-Au electrode in absence (curve b) and presence (curve $\mathrm{c}$ ) of $5 \mu \mathrm{M} \mathrm{AA}$ in $0.05 \mathrm{M}$ phosphate buffer $\mathrm{pH} 7.4$, at a scan rate of $50 \mathrm{mVs}^{-1}$. 


\section{Electrocatalytic and direct oxidation of AA at mod- ified electrode}

Figure 3 (curve a) shows the electrochemical behavior of AA at bare Au electrode in $0.05 \mathrm{M}$ PBS of $\mathrm{pH} 7.4$ with no defined oxidation peak up to $0.7 \mathrm{~V}$. Curve $\mathrm{b}$ and c show the CVs of the NBMn-PPh modified electrode in $0.05 \mathrm{M}$ phosphate buffer of $\mathrm{pH} 7.4$ in the absence (b) and presence (c) of $0.5 \mu \mathrm{MAA}$ at a scan rate of $50 \mathrm{mVs}^{-1}$. The electrode in the absence of AA shows an approximately irreversible $\mathrm{Mn}(\mathrm{II}) \rightarrow \mathrm{Mn}$ (III) redox transition. While, in the presence of $0.5 \mu \mathrm{M} \mathrm{AA}$, an enhancement in anodic peak current was observed at the same oxidation potential. The increased oxidation current is due to the reaction between the oxidized form of the electrocatalyst (i.e., [Mn(III)-complex]) and AA that results in the formation of reduced form of electrocatalyst. Finally, there-oxidation of product of electrocatalytic oxidation of AA causes an increase in the anodic peak current.

Figure 4 shows the CVs of the modified electrode in 0.05 $\mathrm{M}$ phosphate buffer solution of $\mathrm{pH} 7.4$ containing 1.0 to $265.0 \mu \mathrm{M}$ of AA at a scan rate of $50 \mathrm{mVs}^{-1}$. As is obvious, along with the main EO peak for low concentrations at 380
$\mathrm{mV}$, another lower sensitive peak current at higher concentration around $280 \mathrm{mV}$ was began to appear. Appearance of this peaks at higher concentrations and at less positive potentials would frustrate the electrocatalytic oxidation process will be continue. This peak is related to DO of AA at surface of nanostructure film. With a view to gathering further evidence and the approving that the formation of other forms of manganese cannot be responsible for this new appeared peak, the consecutive CV in solution containing $80 \mu \mathrm{M}$ AA was recorded and the obtained results revealed no increase in previously appeared peak located ca. $28 \mathrm{mV}$.

The gradual increase of DO peak at $280 \mathrm{mV}$ will rise to cover the EO peak current. Appearing of this peak is due to the synergetic effect of surface structure, great density of redox centers, catalytic effect and large surface to volume, probably. At higher AA concentrations, with applying of less positive e electroactivity of AA at surface of manganese based nanoparticle modified electrodes was reported at neutral $\mathrm{pH}$ potential window, it can benefit from new appeared peak that is directly related to AA electroxidation. Recently, the electroactivity of AA at surface of manganese based nanoparticle modified electrodes was reported at neutral pHs [37].

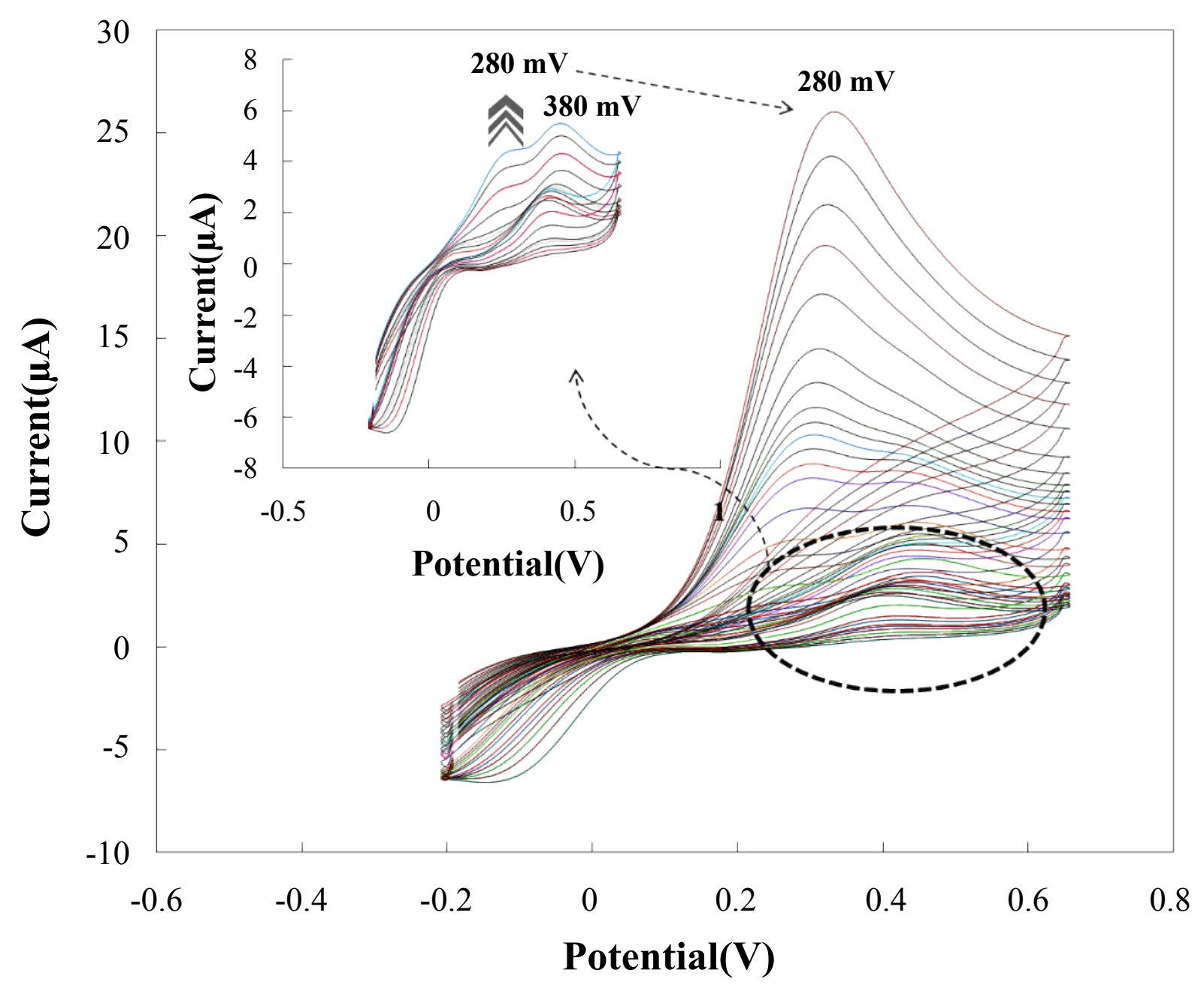

Figure 4: $\mathrm{CVs}$ of the modified electrode in the presence of different $\mathrm{AA}$ concentrations: from 1.0-265.0 $\mu \mathrm{M}$ in $0.050 \mathrm{M}$ phosphate buffer $\mathrm{pH} 7.4$ at a scan rate of $50 \mathrm{mVs}^{-1}$. 

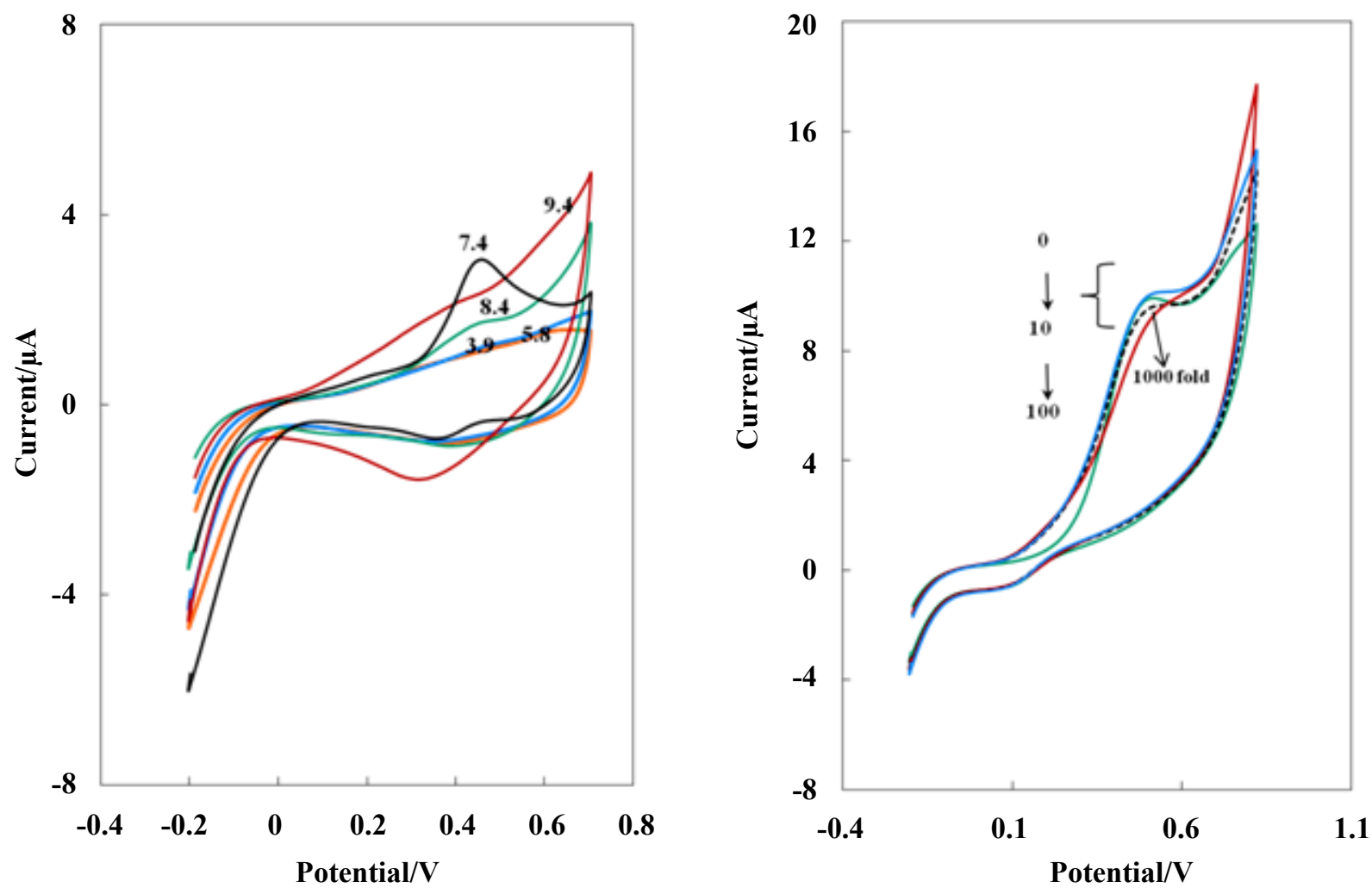

Figure 5: A) Cyclic voltammograms of the NBMn-PPh-Au electrode in various pHs at a scan rate of $50 \mathrm{mVs}^{-1}$; B) Cyclic voltammograms of NBMn-PPh-Au electrode in $5 \mu \mathrm{M} \mathrm{AA}$ in $0.050 \mathrm{M}$ phosphate buffer $\mathrm{pH} 7.4$ solution in presence of 0 , 10,100 and 1000 fold of DA and UA concentrations at a scan rate of $50 \mathrm{mVs}^{-1}$.

\section{Effect of $\mathrm{pH}$ and presence of UA and DA}

To investigate the electrodeposition mechanism, the influence of $\mathrm{pH}$ on the voltammetric behavior of modified electrode was examined in the $\mathrm{pH}$ range 3.8-9.4, and the results showed that, no signal was observed at $\mathrm{pH}<$ 5.8 , by increasing the $\mathrm{pH}$ of the solution up 7.4 the anodic peak currents was reached to maximum (Figure $5 \mathrm{~A}$ ), at higher $\mathrm{pH}$, the peak current was decreased and disappeared that is due to precipitation of manganese with $\mathrm{OH}^{-}$, probably. As the more known represented mechanism in scheme 1 revealed, AA in the more acidic solutions may force the following reaction onto the modified electrode in the backward and greatly decrease anodic peak current as is shown in Figure 5A [21,22].

The initial studies in this work have shown that the electrochemistry of DA can be thoroughly eliminated by the NBMn-PPh film, but the electrochemistry of AA can be totally promoted. Based on this feature, the NBMn$\mathrm{PPh}$ was utilized as a sensor for the highly selective and sensitive determination of AA coexisted with DA. Figure $5 \mathrm{~B}$ shows the CVs of $5.0 \mu \mathrm{M}$ AA in the presence of increasing amounts $(0,10,100$ and 1000 fold) of DA and UA. It can be clearly observed that with increasing concentrations of DA and UA, the redox signals are almost constant (tolerance $<1 \%$ ), suggesting that the co-existed substances in a wide concentration range have no nota- ble interference on the electrochemical response of AA on modified electrode.

\section{EIS study}

EIS is widely used to study features of electrodes to obtain information on electron transfers between the electrolyte and the electrode surface. The semicircular part at higher frequencies corresponds to the electron transfer limited process, and a linear portion at low frequencies resulting from diffusion limited process. The semicircle diameter equals the electron transfer resistance, $R_{c t}$. This resistance reveals the electron transfer resistance of the modified layer. As shown in Figure 6, the Nyquist plot of modified Au electrode and bare Au electrode in $5 \mathrm{mM}\left[\mathrm{Fe}\left(\mathrm{CN}_{6}\right)\right]^{-2} /\left[\mathrm{Fe}\left(\mathrm{CN}_{6}\right)\right]^{-3}$ in the frequency range of $0.1 \mathrm{~Hz}$ to $100,000 \mathrm{~Hz}$, show a straight line in the low frequency domain and a semicircle in the high frequency domain, wherein, only a part of the semicircles can be seen at high frequency due to the limitation of the electrochemical analyzer used here. These illustrate that both diffusion-limiting and electron-transfer-limiting steps exist for the two electrodes. In the high frequency region, it can be clearly inferred that the $\mathrm{R}_{\mathrm{ct}}$ for the modified electrodes is more from $\mathrm{Au}$ bare electrode. The $\mathrm{R}_{\mathrm{ct}}$ values obtained for the Au and Au/RANBMn complex film were about $280 \Omega$ and $4750 \Omega$ that being consistent with the slower rate for the redox process of modified 


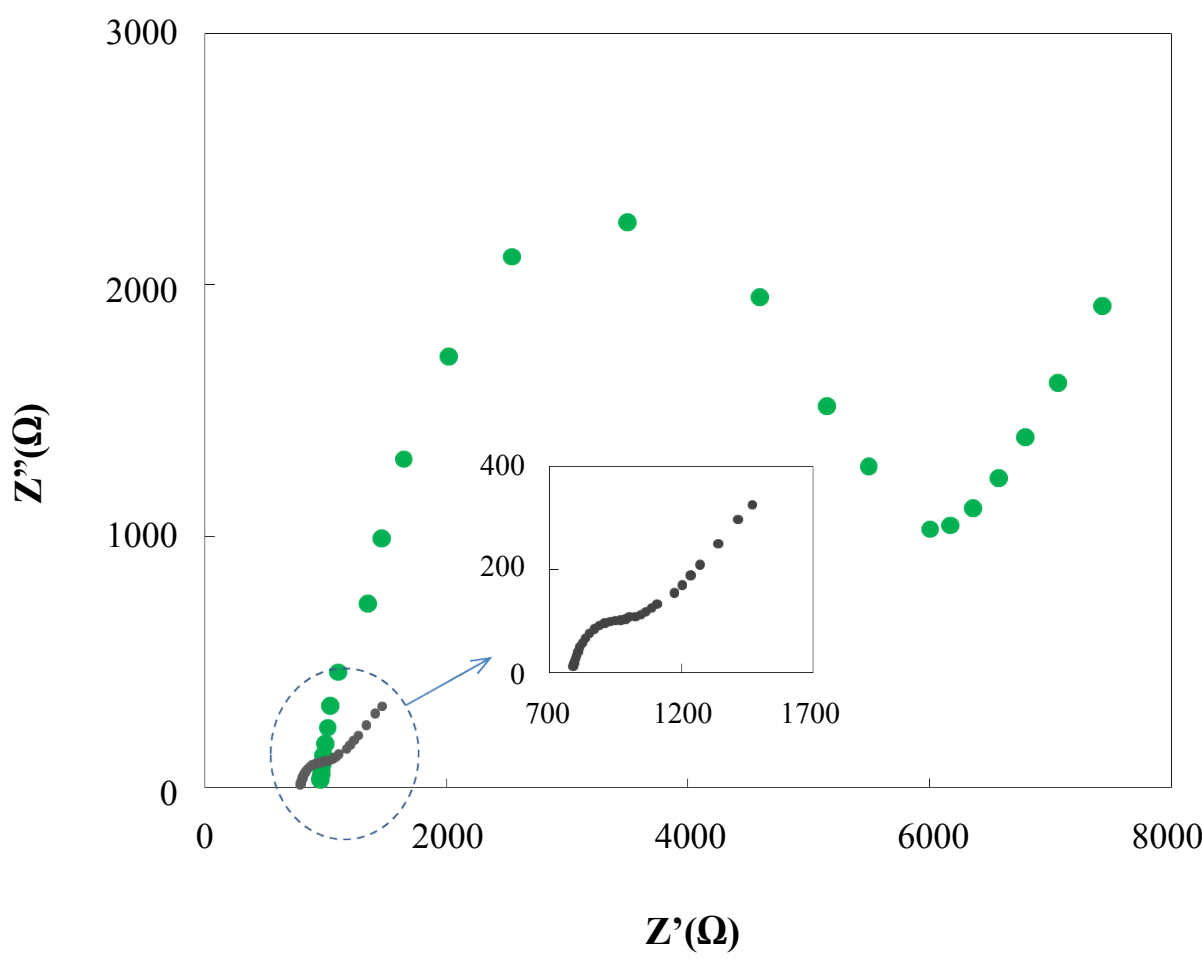

Figure 6: Electrochemical impedance spectroscopy of a Au (inset) and NBMn-PPh-Au in the presence of a solution of 5.0 $\mathrm{mmol} / \mathrm{L}[\mathrm{Fe}(\mathrm{CN}) 6]^{3-14-}+0.1 \mathrm{~mol} / \mathrm{L} \mathrm{KCl}$ with the frequencies ranging from 100.000 to $0.1 \mathrm{~Hz}$.

electrode, as pointed out above. This demonstrates that the electropolymerization of $\mathrm{Mn}(\mathrm{III})$-porphyrin complex, cause to increasing of electron transfer resistance at electrode-electrolyte interface. Furthermore, the coverage degree $(\theta)$ of the electrode surface was calculated through the increase extent of charge transfer resistance according to the following equation [38]:

$$
\theta=1-\frac{\mathrm{R}_{\mathrm{et}}^{\text {bare }}}{\mathrm{R}_{\mathrm{et}}^{\text {modified }}}
$$

Where $\mathrm{R}_{\mathrm{et}}^{\text {bare }}$ and $\mathrm{R}_{\mathrm{et}}^{\text {modified }}$ are the charge-transfer resistance measured mat bare $\mathrm{Au}$ and NBMn-PPh$\mathrm{Au}$, respectively. From the values of $\mathrm{R}_{\mathrm{et}}$ on bare $\mathrm{Au}$ and $\mathrm{NBMn}-\mathrm{PPh}-\mathrm{Au}$, the value of $\theta$ was then calculated to be $94.06 \%$ via Eq. (2), which clearly shows that NBMn-PPh has occupied most of the Au surface by the electropolymerization method.

\section{Effect of scan rate in buffer}

Cyclic voltammograms of the NBMn-PPh electrode in a PBS showed an irreversible oxidation peak at $0.4 \mathrm{~V}$. Figure $7 \mathrm{~A}$ shows the CVs of the modified electrode in the PBS (pH 7.0) at different scan rates. The anodic peak potential shifted toward the positive direction as the scan rate increased, $\mathrm{E}_{\mathrm{p}}$ was changed from 403 to $558 \mathrm{mV}$ during scan rate variation. This deviation of the redox process from the ideal surface redox process, appearing even at low scan rates may be attributed to the limitations associated with charge transfer kinetics $[39,40]$.
Furthermore, this indicates a relatively slow electron exchange process at the interface between the electrode substrate and manganese redox center. A linear relationship was observed with the square root of the scan rate in the range from 10 to $300 \mathrm{mV} / \mathrm{s}\left(\mathrm{i}_{\mathrm{pa}}=1.81 \mathrm{v}^{1 / 2}+2.246, \mathrm{R}^{2}\right.$ $=0.994$ ), suggesting a diffusion controlled process for the sensor (Figure 7B).

\section{Effect of scan rate of AA}

Figure $8 \mathrm{~A}$ illustrates CVs of $8.0 \mu \mathrm{M}$ AA using modified electrode that recorded at potential sweep rates ranging from 10 to $300 \mathrm{mVs}^{-1}$. The oxidation current of AA on the modified surface increased linearly with the square root of the potential sweep rate (Figure 8B), which indicated the mass transfer controlled process [41]. In addition, it can be seen that, with the increasing scan rate, the anodic peak potential shifts toward positive potentials, suggesting a kinetic limitation in the reaction between the redox sites of the NBMn-PPh-Au electrode and AA (Figure $8 \mathrm{C}$ ). A plot of the scan rate normalized current $\left(\mathrm{I} / \mathrm{V}^{1 / 2}\right)$ vs. scan rate (Figure $8 \mathrm{D}$ ) exhibits the typical shape of an electrochemical-chemical catalytic process $\left(E^{\prime} c\right)$ [4]. The value of the transfer coefficient of electrode reaction can be evaluated from the following equation $[42,43]$ :

$\mathrm{Ep}=\left[\frac{2.303 \mathrm{RT}}{2(1-\alpha) \mathrm{nF}}\right](\log v)+$ constant $\left[\frac{\mathrm{dE}_{\mathrm{p}}}{\mathrm{d} \log v}=\frac{\mathrm{b}}{2}\right]$

In the above equation, Ep, $v, \alpha$ and $n$ represent the anodic peak potential for AA oxidation, the scan rate, 

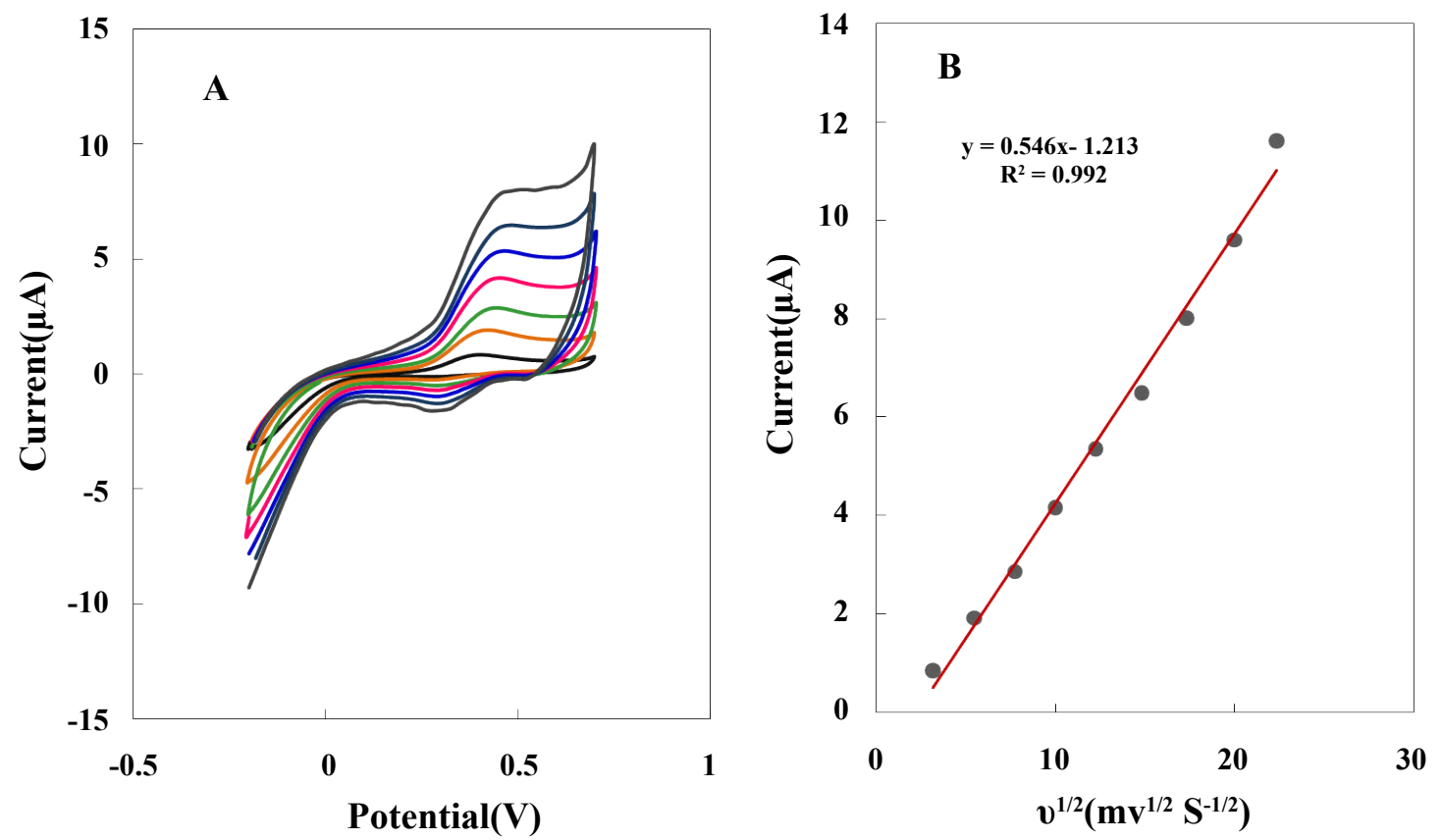

Figure 7: A) Cyclic voltammograms of NBMn-PPh-Au in pH 7.4 buffer with scan rates of 10, 30, 60, 100, 150, 220 and 300 $\mathrm{mVs}^{-1}$; B) Plot of scan rate dependency of peak currents.
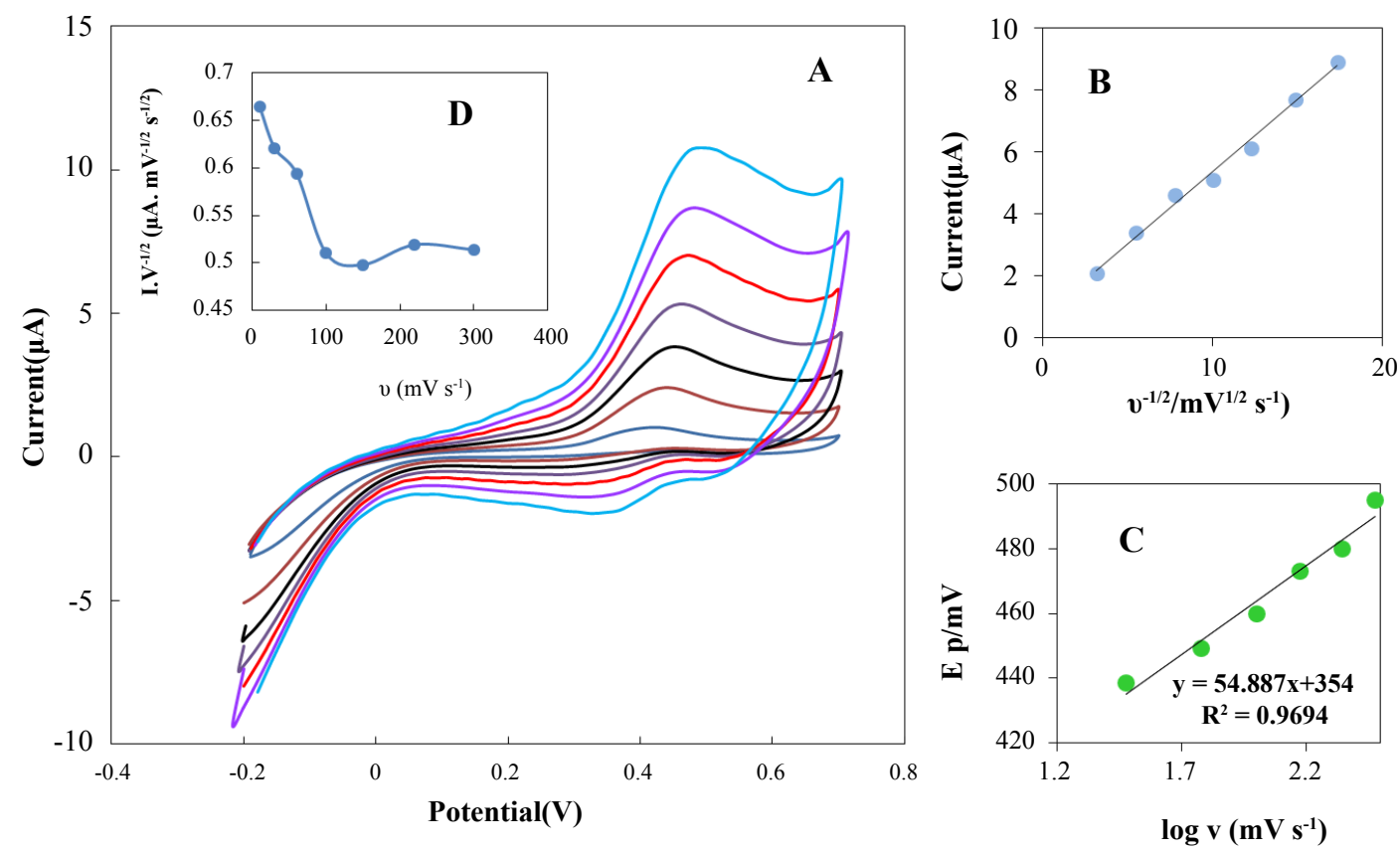

Figure 8: A) Cyclic voltammograms of the modified electrode in the presence of $8.0 \mu$ MAA at various scan rates: 10, 30, 60, 100, 150,220 and $300 \mathrm{mVs}^{-1}$ in $\mathrm{pH} 7.4$ buffer solution; B) The variation of anodic peak currents vs. square root of potential scan rate; C) The dependence of the anodic peak potential vs. $\log (\mathrm{u})$; D) The anodic current function $\left(\mathrm{I} / \mathrm{V}^{1 / 2}\right)$ vs. potential sweep rate.

the charge transfer coefficient and the number of electron transferred in the rate-determining step, respectively. The other terms signify their usual meaning and the term $2.303 \mathrm{RT} /(1-\alpha) \mathrm{nF}$ is equal to $\mathrm{b}$. Where $\mathrm{b}$ indicates the Tafel slope. From eqn (3), the slope of Ep vs. $\log v$ is $\mathrm{b} / 2$, which was found to be $54.88 \mathrm{mV}$ from Figure $8 \mathrm{C}$ and therefore $b$ becomes $109.76 \mathrm{mV}(\mathrm{b} / 2=54.88)$. Using the dependency of anodic peak potential on the natural logarithm of the potential sweep rate (Figure $8 \mathrm{C}$ ), the value of electron transfer coefficient ( $\alpha$ ) was estimated at 0.453 . Also, the obtained value of transfer coefficient from the recorded I-E curve of electrocatalytic oxidation of AA (slope of log I vs. E plot) confirms the above reported value (0.471).

\section{Amperometric determination of AA}

Figure 9A shows the amperometric response of the modified electrode at $0.4 \mathrm{~V}$ to the successive addition of 

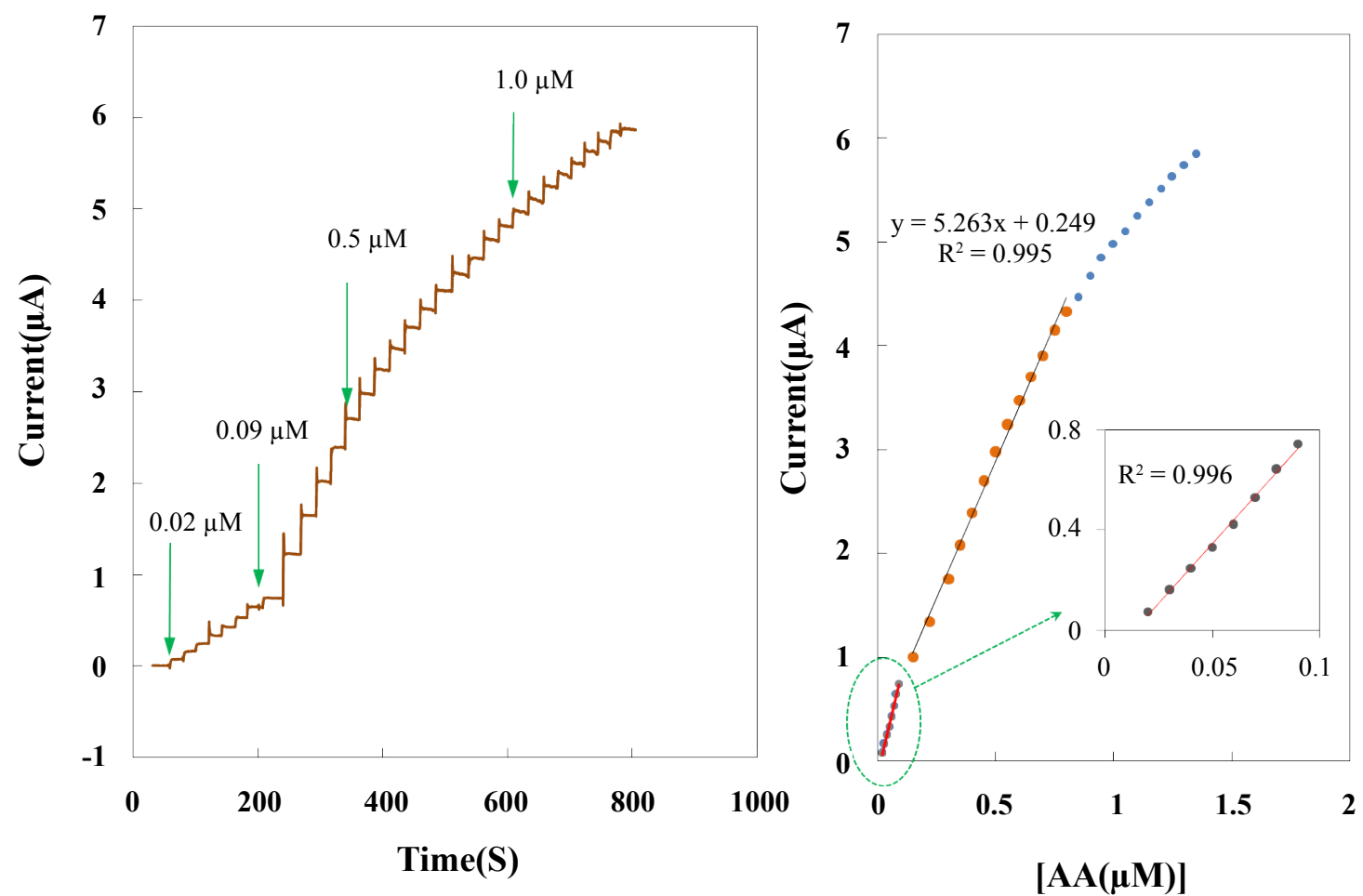

Figure 9: Amperometric response at rotating NBMn-PPh-Au electrode in the presence of different $\mathrm{AA}$ concentration in $\mathrm{pH} 7.4$ buffer solution; B) Plot of amperometric currents vs. AA concentrations.

different concentrations of AA in PBS ( $\mathrm{pH}$ 7.4). Upon addition of an aliquot of $\mathrm{AA}$ to the stirring solution, the oxidation current of the sensors increased steeply to reach a stable value. Figure 9B displays the calibration curve of the amperometric response of the sensor to the concentration of AA. The linear range of the proposed sensor for the determination of AA was $0.02-0.8 \mu \mathrm{M}$ with a detection limit of $8.4 \mathrm{nM}$ estimated at $\mathrm{S} / \mathrm{N}$ of 3 . The data from the proposed electrodes in this study is compared to data from several other reported electrochemical AA sensors [44-72] in Table 2, showing that the electrode investigated in this study compare favorably to many other examples in the literature.

\section{Interferences study}

One main problem of AA sensors is simultaneous oxidation of other organic substances in the blood that oxidize at a comparable potential to AA. Other materials in the blood such as dopamine, uric acid and glucose although at low concentrations relative to AA might, in principle, interfere with determination of AA. Susceptibility of proposed sensor to determine low level AA concentrations, allow the diluting of real samples and therefore decrease the effect of coexisting interferences on the AA amperometry response. The possible interference of foregoing compounds was studied on the functioning of the proposed sensor and result is listed in Table 3. Compared to the other interfering species, the current generated due to dopamine are negligible.

\section{Real sample analysis}

The analytical utility of the proposed sensor was assessed by the analysis of AA in different serum samples prepared as described in Section 2.5, Table 4 shows the results obtained for the AA content of the real samples. As it is obvious, the obtained recoveries are in the range of $97-103 \%$. It was conclude that the modified electrode may have applications in selective AA monitoring in real samples.

\section{Repeatability, reproducibility and stability}

The repeatability and stability of the proposed sensor were investigated in the presence of $40.0 \mathrm{nM}$ AA by amperometric measurements. The proposed sensor showed an acceptable repeatability with a Relative Standard Deviation (RSD) of $2.8 \%$ for 10 successive assays. A RSD of $4.2 \%$ was obtained with five sensors prepared independently using the same procedure. When the modified electrode was not in use, it was stored in PBS (pH 7.4) at $20{ }^{\circ} \mathrm{C}$. The sensor retained more than $95.0 \%$ of its initial response to the oxidation of AA after a three-week period storage.

\section{Conclusions}

The micro/nanoelectrodes are also used widely in electroanalysis due to their reduced ohmic drop and charging current, increased temporal resolution and increased current densities. Randomly distributed arrays of nanobar electrodes, $62 \pm 5 \mathrm{~nm}$ in diameter have been 
Table 2: Merits of recently published comparable methods for determination of AA.

\begin{tabular}{|c|c|c|c|c|c|c|}
\hline Electrode & Method $(\mu \mathrm{M})$ & Linear Range $(\boldsymbol{\mu} \mathrm{M})$ & LOD $(\mu \mathrm{M})$ & Potential & Year & Ref. \\
\hline $\begin{array}{l}\text { Bismuth sulfide nanorod modified glassy carbon } \\
\text { electrode }\end{array}$ & Amperometry & $1-1000$ & 0.83 & 0.13 & 2012 & [44] \\
\hline $\begin{array}{l}\mathrm{N} \text {-silicon electrode modified by platinum and cobalt } \\
\text { hexacyanoferrate films }\end{array}$ & $\begin{array}{l}\text { Photo current Am- } \\
\text { perometry }\end{array}$ & $1-1000$ & 1.00 & - & 2012 & [45] \\
\hline $\begin{array}{l}\text { Gold decorated } \mathrm{SiO}_{2} @ \text { polyaniline } \\
\text { core-shell microspheres }\end{array}$ & Amperometry & $150-8000$ & 3.775 & 0.38 & 2013 & [46] \\
\hline $\begin{array}{l}\text { Nanoflower-like dendritic Au and polyaniline com- } \\
\text { posite nanosheets }\end{array}$ & Amperometry & $10-12000$ & 8.2 & -0.2 & 2013 & [47] \\
\hline $\begin{array}{l}\text { Flexible poly(dimethylsioxane) (PDMS)-based gold } \\
\text { electrode }\end{array}$ & Amperometry & $0.66-2600$ & 0.2 & 0.32 & 2012 & [48] \\
\hline $\begin{array}{l}\text { Sodium dodecyl sulfate modified carbon nanotubes } \\
\text { paste electrode }\end{array}$ & Cyclic voltammetry & $1-28$ & 0.33 & 0.05 & 2014 & [49] \\
\hline $\begin{array}{l}\text { PbS nanoparticle-decorated } \\
\text { Schiff-base-modified carbon-paste electrode }\end{array}$ & $\begin{array}{l}\text { Differential pulse } \\
\text { voltammetry }\end{array}$ & $2.5-1005$ & 0.018 & 0.4 & 2015 & [50] \\
\hline $\begin{array}{l}\text { Cobalt(II) phthalocyanine-MWCNS glassy carbon } \\
\text { electrode }\end{array}$ & Amperometry & $10-2600$ & 1.0 & 0.19 & 2012 & [51] \\
\hline $\begin{array}{l}\text { Branched polyethylenimine cross-linked with eth- } \\
\text { ylene glycol diglycidyl ether }\end{array}$ & Cyclic voltammetry & $1-5000$ & 1.0 & 0.24 & 2013 & [52] \\
\hline Methionine modified carbon paste electrode & $\begin{array}{l}\text { Differential pulse } \\
\text { voltammetry }\end{array}$ & $5-120$ & 3.5 & 0.38 & 2012 & [53] \\
\hline $\begin{array}{l}\text { Polyaniline/polyacrylic acid/multi-walled carbon } \\
\text { nanotube modified electrodes }\end{array}$ & $\begin{array}{l}\text { Differential pulse } \\
\text { voltammetry }\end{array}$ & $1-1000$ & 0.25 & 0.3 & 2012 & [54] \\
\hline $\begin{array}{l}\text { Immobilization of Ascorbate Oxidase into the Bio- } \\
\text { compatible Sandwich-Type Composite Film }\end{array}$ & Amperometry & $0.4-1000$ & 0.087 & 0.05 & 2012 & [55] \\
\hline $\begin{array}{l}\text { Over-oxidized polypyrrole and palladium nanoparti- } \\
\text { cles composites }\end{array}$ & Amperometry & $1-520,120-1600$ & 1.0 & 0.0 & 2012 & [56] \\
\hline Platinum Nanoparticles Modified Au electrode & Amperometry & $0.6-3.267$ & 0.0019 & 0.2 & 2013 & [57] \\
\hline Ionic liquid-carbon nanotube composite electrode & $\begin{array}{l}\text { Differential pulse } \\
\text { voltammetry }\end{array}$ & $3.0-4200$ & 1.0 & 0.005 & 2012 & [58] \\
\hline $\begin{array}{l}\text { Cobalt species in nanodimensional pores of mor- } \\
\text { denite zeolite as modified carbon paste electrode }\end{array}$ & Cyclic voltammetry & $45-500$ & 2.3 & 0.34 & 2012 & [59] \\
\hline Glassy carbon electrodes modified with MWCNT & $\begin{array}{l}\text { Square-wave vol- } \\
\text { tammetry }\end{array}$ & $4.7-5000$ & 1.4 & 0.315 & 2012 & [60] \\
\hline $\begin{array}{l}\text { Cobalt(II) tetra-neopentyloxyphthalocya- } \\
\text { nine-multi-walled Carbon nanotubes glassy carbon } \\
\text { electrode }\end{array}$ & Amperometry & $10-1600$ & 5.0 & 0.215 & 2012 & [61] \\
\hline $\begin{array}{l}\text { Nickel, Copper and Manganese Hexacyanoferrate } \\
\text { with Poly(3,4-ethylenedioxythiophene) Hybrid Film }\end{array}$ & & $5-300,1800-18000$ & 1.0 & 0.2 & 2012 & [62] \\
\hline $\begin{array}{l}\text { Glassy carbon electrode modified with a poly- } \\
\text { aniline doped with silicotungstic acid and carbon } \\
\text { nanotubes }\end{array}$ & Amperometry & $1-10,10-9000$ & 0.51 & 0.4 & 2013 & [63] \\
\hline A lithium-doped tantalum oxide film coated electrode & Cyclic voltammetry & $5000-12000$ & - & 0.42 & 2013 & [64] \\
\hline Carbon-supported $\mathrm{NiCoO}_{2}$ nanoparticles & Amperometry & $10-2630$ & 0.5 & -0.2 & 2014 & [65] \\
\hline $\begin{array}{l}\text { Molecularly imprinted poly(o-phenylenedi- } \\
\text { amine-co-o-aminophenol) }\end{array}$ & $\begin{array}{l}\text { Differential pulse } \\
\text { voltammetry }\end{array}$ & $100-10000$ & 36.4 & 0.366 & 2014 & [66] \\
\hline $\begin{array}{l}\text { Nickel hexacyanoferrate/layered double hydroxide } \\
\text { hybrid film/gold electrode }\end{array}$ & $\begin{array}{l}\text { Chronoamperom- } \\
\text { etry }\end{array}$ & $100-3500$ & 21 & 0.32 & 2014 & [67] \\
\hline $\begin{array}{l}\text { Self-powered biosensor with a Prussian blue elec- } \\
\text { trochromic display }\end{array}$ & Cyclic voltammetry & $10-350$ & 4.0 & 0.3 & 2014 & [68] \\
\hline $\begin{array}{l}\text { Titanium dioxide nanoparticle/gold nanoparticle/ } \\
\text { MWCNT nanocomposites }\end{array}$ & $\begin{array}{l}\text { Differential pulse } \\
\text { voltammetry }\end{array}$ & 0.01 to 0.08 & 0.01 & - & 2013 & [69] \\
\hline $\begin{array}{l}\text { Glassy carbon electrode modified with the nick- } \\
\text { el(II)-bis(1,10-phenanthroline) complex and MWCNT }\end{array}$ & Amperometry & $10-630$ & 4 & 0.31 & 2013 & {$[70]$} \\
\hline $\begin{array}{l}\text { Poly(Nile blue A) and functionalised multi-walled } \\
\text { carbon nanotube modified electrode }\end{array}$ & Amperometry & $10-120$ & 1.6 & 0.1 & 2013 & [71] \\
\hline $\begin{array}{l}\text { Poly(bromocresol purple) } \\
\text { film modified glassy carbon electrode }\end{array}$ & $\begin{array}{l}\text { Differential pulse } \\
\text { voltammetry }\end{array}$ & $20-700$ & 6.5 & -0.01 & 2013 & [72] \\
\hline Nanobar manganese(III)-porphyrin platform & Amperometry & $0.02-0.8$ & 0.0084 & 0.4 & - & $\begin{array}{l}\text { This } \\
\text { work }\end{array}$ \\
\hline
\end{tabular}


Table 3: Effect of co-existing compounds in the amperometric determination of $0.2 \mu \mathrm{M}$ of AA with the proposed electrode.

\begin{tabular}{|l|l|l|}
\hline Interference & $\begin{array}{l}\text { Concentration } \\
(\boldsymbol{\mu} \mathbf{M})\end{array}$ & $\begin{array}{l}\text { Variation of } \\
\text { amperometric peak (\%) }\end{array}$ \\
\hline Dopamine & 25 & 0.83 \\
\hline Uric acid & 20 & 1.5 \\
\hline Glucose & 20 & 4.5 \\
\hline Sucrose & 20 & 1.2 \\
\hline Cysteine & 20 & 4.1 \\
\hline Tryptophan & 20 & 5 \\
\hline Vitamin $\mathrm{B}_{1}$ & 20 & 2.7 \\
\hline Vitamin $\mathrm{B}_{6}$ & 20 & 3.8 \\
\hline Oxalic acid & 20 & 2.8 \\
\hline
\end{tabular}

Table 4: Amperometric determination of low levels AA using proposed electrode in diluted AA containing serum samples.

\begin{tabular}{|l|l|l|l|}
\hline Sample & $\begin{array}{l}\text { Added } \\
\text { (nM) }\end{array}$ & Found (nM) & Recovery (\%) \\
\hline Serum sample 1 & 0 & $64.1( \pm 3.89)$ & - \\
\hline & 45 & $107.7( \pm 5.05)$ & 97.1 \\
\hline Serum sample 2 & 0 & $158.9( \pm 6.84)$ & 97.8 \\
\hline & 40 & $30.6( \pm 1.82)$ & - \\
\hline & 175 & $68.4( \pm 3.17)$ & 98.2 \\
\hline Serum sample 3 & 0 & $207.8( \pm 8.44)$ & 101.0 \\
& 37.5 & $145.6( \pm 6.70)$ & - \\
\hline & 325 & $466.1( \pm 14.35)$ & 98.3 \\
\hline
\end{tabular}

constructed using an electropolymerization of manganese(III)-porphyrin. The nanoelectrode arrays are routinely used in analytical electrochemistry because of their many advantageous properties. Nonlinear diffusion and edge effects lead to an increase in current density and enhanced sensitivity. The propose sensor is capable of electrocatalytic and direct oxidation of AA. In this work, overlapping elliptical diffusion zones cause to assessment low-level detection limits. However, to take advantage of the ultra-microelectrodes' they must retain sufficient separation or more adjacent to be diffusionally independent

\section{Acknowledgements}

The support of this work by the Razi University research council and Iran Nanotechnology Initiative Council is greatly acknowledged.

\section{References}

1. C Amatore (1995) Physical electrochemistry: Principles, methods and applications. In: I Rubenstein, Marcel Dekker, New York, 131.

2. RM Wightman, DO Wip (1989) Electroanalytical Chemistry. In: AJ Bard, Marcel Dekker, New York, 267.

3. AJ Bard, LR Faulkner (2001) Electrochemical methods, fundamentals and applications. ( $2^{\text {nd }}$ edn), John Wiley \& Sons Inc, New York.
4. MB Gholivand, A Pashabadi, A Azadbakht, S Menati (2011) A nano-structured Ni (II)-ACDA modified gold nanoparticle self-assembled electrode for electrocatalytic oxidation and determination of tryptophan. Electrochimica Acta 56: 4022-4030.

5. TJ Davies, S Ward-Jones, CE Banks, J Del Campo, R Mas, et al. (2005) The cyclic and linear sweep voltammetry of regular arrays of micro disc electrodes: fitting of experimental data. Journal of Electroanalytical Chemistry 585: 51-62.

6. TJ Davies, CE Banks, RG Compton (2005) Voltammetry at spatially heterogeneous electrodes. J Solid State Electrochem 9: 797-808.

7. AO Simm, S Ward-Jones, CE Banks, RG Compton (2005) Novel methods for the production of silver microelectrode-arrays: their characterization by atomic force microscopy and application to the electro-reduction of halothane. Analytical Sciences 21: 667-671.

8. CM Welch, RG Compton (2006) The use of nanoparticles in electroanalysis: a review. Anal Bioanal Chem 384: 601-619.

9. S Klebanoff, D Dziewiatkowski, G Okinaka (1958) The effect of ascorbic acid oxidation on the incorporation of sulfate by slices of calf costal cartilage. J Gen Physiol 42: 303-318.

10. BA Eipper, RE Mains, CC Glembotski (1983) Identification in pituitary tissue of a peptide alpha-amidation activity that acts on glycine-extended peptides and requires molecular oxygen, copper, and ascorbic acid. Proc Natl Acad Sci USA 80: 5144-5148.

11. MB Davies, J Austin, DA Partridge (1991) Vitamin C: its chemistry and biochemistry. The Royal Society of Chemistry, Cambridge.

12. T Wu, Y Guan, J Ye (2007) Determination of flavonoids and ascorbic acid in grapefruit peel and juice by capillary electrophoresis with electrochemical detection. Food Chemistry 100: 1573-1579.

13. X Wu, Y Diao, C Sun, J Yang, Y Wang, et al. (2003) Fluorimetric determination of ascorbic acid with o-phenylenediamine. Talanta 59: 95-99.

14. N Anastos, NW Barnett, BJ Hindson, CE Lenehan, SW Lewis (2004) Comparison of soluble manganese(IV) and acidic potassium permanganate chemiluminescence detection using flow injection and sequential injection analysis for the determination of ascorbic acid in Vitamin $\mathrm{C}$ tablets. Talanta 64: 130-134.

15. L Nováková, D Solichová, P Solich (2009) Hydrophilic interaction liquid chromatography - charged aerosol detection as a straightforward solution for simultaneous analysis of ascorbic acid and dehydroascorbic acid. Journal of Chromatography A 1216: 4574-4581.

16. J Kulys, EJ D'Costa (1991) Printed electrochemical sensor for ascorbic acid determination. Analytica Chimica Acta 243: 173-178.

17. SA Kumar, PH Lo, SM Chen (2008) Electrochemical selective determination of ascorbic acid at redox active polymer modified electrode derived from direct blue 71. Biosensors and Bioelectronics 24: 518-523.

18. D Ragupathy, AI Gopalan, KP Lee (2010) Electrocatalytic oxidation and determination of ascorbic acid in the presence of dopamine at multiwalled carbon nanotube-silica network-gold nanoparticles based nanohybrid modified electrode. Sensors and Actuators B: Chemical 143: 696-703. 
19. D Wen, S Guo, S Dong, E Wang (2010) Ultrathin Pd nanowire as a highly active electrode material for sensitive and selective detection of ascorbic acid. Biosensors and Bioelectronics 26: 1056-1061.

20. A Vulcu, C Grosan, LM Muresan, S Pruneanu, L Olenic, et al. (2013) Modified gold electrodes based on thiocytosine/ guanine-gold nanoparticles for uric and ascorbic acid determination. Electrochimica Acta 88: 839-846.

21. S Sharifian, A Nezamzadeh-Ejhieh (2016) Modification of carbon paste electrode with Fe (III)-clinoptilolite nano-particles for simultaneous voltammetric determination of acetaminophen and ascorbic acid. Materials Science and Engineering: C 58: 510-520.

22. S Sharafzadeh, A Nezamzadeh-Ejhieha (2015) Using of anionic adsorption property of a surfactant modified clinoptilolite nano-particles in modification of carbon paste electrode as effective ingredient for determination of anionic ascorbic acid species in presence of cationic dopamine species. Electrochimica Acta 184: 371-380.

23. L Huang, S Jiao, M Li (2014) Determination of uric acid in human urine by eliminating ascorbic acid interference on copper (II)-polydopamine immobilized electrode surface. Electrochimica Acta 121: 233-239.

24. X Zhu, Y Liang, X Zuo, R Hu, X Xiao (2014) Novel water-soluble multi-nanopore graphene modified glassy carbon electrode for simultaneous determination of dopamine and uric acid in the presence of ascorbic acid. Electrochimica Acta 143: 366-373.

25. M Shamsipur, A Pashabadi, F Molaabasi, S Hosseinkhani (2017) Impedimetric monitoring of apoptosis using cytochrome-aptamer bioconjugated silver nanocluster. Biosensors and Bioelectronics 90: 195-202.

26. M Shamsipur, A Pashabadi, F Molaabasi (2015) A novel electrochemical hydrogen peroxide biosensor based on hemoglobin capped gold nanoclusters-chitosan composite. RSC Adv 5: 61725-61734.

27. M Shamsipur, A Pashabadi, AA Taherpour, B Hemmateenejad, T Khosousi, et al. (2017) Synthesis and characterization of glucose-capped CdSe quantum dots. Electrochemical and computational studies of corresponding carbon-ionic liquid electrode for quantitative determination of minoxidil. Journal of Electroanalytical Chemistry 778 : 116-125.

28. M Shamsipur, A Pashabadi, AA Taherpour, K Bahrami, H Sharghi (2017) Manganese mediated oxidation of progesterone in alkaline medium: Mechanism study and quantitative determination. Electrochimica Acta 225: 292-302.

29. M Pagels, CE Hall, NS Lawrence, A Meredith, TGJ Jones, et al. (2005) All-diamond microelectrode array device. Anal Chem 77: 3705-3708.

30. M Lovrica, S Komorsky-Lovrica, RG Compton (2005) Electrodes covered with random arrays of microdroplets: heterogeneous electron transfer coupled to catalytic reaction at the liquid/liquid interface in the prism film geometry approximation. Electrochimica Acta 50: 1377-1381.

31. TJ Davies, BA Brookes, AC Fisher, $K$ Yunus, SJ Wilkins, et al. (2003) A Computational and Experimental Study of the Cyclic Voltammetry Response of Partially Blocked Electrodes. Part II: Randomly Distributed and Overlapping Blocking Systems. J Phys Chem B 107: 6431-6444.
32. TJ Davies, RG Compton (2005) The cyclic and linear sweep voltammetry of regular and random arrays of microdisc electrodes: Theory. Journal of Electroanalytical Chemistry 585: 63-82.

33. AO Simm, CE Banks, S Ward-Jones, TJ Davies, NS Lawrence, et al. (2005) Boron- doped diamond microdisc arrays: electrochemical characterisation and their use as a substrate for the production of microelectrode arrays of diverse metals $(\mathrm{Ag}, \mathrm{Au}, \mathrm{Cu})$ via electrodeposition. Analyst 130: 1303-1311.

34. D Menshykau, XJ Huang, NV Rees, FJ del Campo, F Munoz, et al. (2009) Investigating the concept of diffusional independence. Potential step transients at nano-and micro-electrode arrays: theory and experiment. Analyst 134: 343-348.

35. TJ Davies, ER Lowe, SJ Wilkins, RG Compton (2005) Voltammetric sizing of inert particles. Chemphyschem 6: 13401347.

36. A Einstein (1956) Investigations on the Theory of the Brownian movement. Dover Publications, New York.

37. R Jothiramalingam, MK Wang (2010) Manganese oxide nanocomposites with improved surface area prepared by one-pot surfactant route for electro catalytic and biosensor applications. J Porous Mater 17: 677-683.

38. MA Wilson, A Pohorille, LR Pratt (1987) Molecular dynamics of the water liquid-vapor interface. J Phys Chem 91: 4873-4878.

39. M Nosuhi, A Nezamzadeh-Ejhieh (2017) High catalytic activity of $\mathrm{Fe}(\mathrm{II})$-clinoptilolite nanoparticles for indirect voltammetric determination of dichromate: Experimental design by response surface methodology (RSM). Electrochimica Acta 223: 47-62.

40. F Alidusty, A Nezamzadeh-Ejhieh (2016) Considerable decrease in overvoltage of electro-catalytic oxidation of methanol by modification of carbon paste electrode with Cobalt (II)-clinoptilolite nanoparticles. International Journal of $\mathrm{Hy}$ drogen Energy 41: 6288-6299.

41. M Saadat, A Nezamzadeh-Ejhieh (2016) Clinoptilolite nanoparticles containing HDTMA and Arsenazo III as a sensitive carbon paste electrode modifier for indirect voltammetric measurement of Cesium ions. Electrochimica Acta 217: 163-170.

42. JA Harrison, ZA Khan (1970) The oxidation of hydrazine on platinum in acid solution. Journal of Electroanalytical Chemistry and Interfacial Electrochemistry 28: 131-138.

43. J Ren, H Zhang, Q Ren, C Xia, J Wan, et al. (2001) Study of the catalytic electro-oxidation of ascorbic acid on an electrode modified by macrocyclic compounds of $\mathrm{Fe}$ (III), Mn (III), Ni (II), and Co (II) with TBP. Journal of Electroanalytical Chemistry 504: 59-63.

44. YP Dong, L Huang, J Zhang, XF Chu, QF Zhang (2012) Electro-oxidation of ascorbic acid at bismuth sulfide nanorod modified glassy carbon electrode. Electrochimica Acta 74: 189-193.

45. H Li, Q Gao, L Chen, W Hao (2012) Photocurrent determination ascorbic acid using an n-silicon electrode modified by platinum and cobalt hexacyanoferrate films. Sensors and Actuators B: Chemical 173: 540-546.

46. Chang-Jian Weng, Ya-Lun Chen, Chao-Ming Chien, ShengChieh Hsu, Yu-Sian Jhuo, et al. (2013) Preparation of gold 
decorated SiO 2@ polyaniline core-shell microspheres and application as a sensor for ascorbic acid. Electrochimica Acta 95: 162-169.

47. H Zhang, F Huang, S Xu, Y Xia, W Huang, et al. (2013) Fabrication of nanoflower-like dendritic $\mathrm{Au}$ and polyaniline composite nanosheets at gas/liquid interface for electrocatalytic oxidation and sensing of ascorbic acid. Electrochemistry Communications 30: 46-50.

48. D Fan, Lianhua Bi, F Tang, H Zheng, Q Xub, et al. (2012) I-Cysteine modified flexible PDMS-gold electrode for sensing ascorbic acid and copper. Sensors and Actuators B: Chemical 161: 1124-1128.

49. JG Manjunatha, M Deraman, NH Basri, NS Mohd Nor, I Abu Talib, et al. (2014) Sodium dodecyl sulfate modified carbon nanotubes paste electrode as a novel sensor for the simultaneous determination of dopamine, ascorbic acid, and uric acid. Comptes Rendus Chimie 17: 465-476.

50. N Soltani, N Tavakkoli, N Ahmadi, N Davar (2015) Simultaneous determination of acetaminophen, dopamine and ascorbic acid using a $\mathrm{PbS}$ nanoparticles Schiff base-modified carbon paste electrode. Comptes Rendus Chimie 18: 438-448.

51. X Zuoa, H Zhang, N Li (2012) An electrochemical biosensor for determination of ascorbic acid by cobalt (II) phthalocyanine-multi-walled carbon nanotubes modified glassy carbon electrode. Sensors and Actuators B: Chemical 161: 1074-1079.

52. V Ganesana, PK Rastogia, R Guptaa, MT Meredith, SD Minteer (2013) lon exchange voltammetry at branched polyethylenimine cross-linked with ethylene glycol diglycidyl ether and sensitive determination of ascorbic acid. Electrochimica Acta 105: 31-39.

53. BK Chethana, YA Naik (2012) Electrochemical oxidation and determination of ascorbic acid present in natural fruit juices using a methionine modified carbon paste electrode. Anal Methods 4: 3754-3759.

54. I Tiwari, KP Singh, M Singh, CE Banks (2012) Polyaniline/ polyacrylic acid/multi-walled carbon nanotube modified electrodes for sensing ascorbic acid. Anal Methods 4: 118-124.

55. Y Wen, J Xu, M Liu, D Li, H He (2012) Amperometric vitamin $\mathrm{C}$ biosensor based on the immobilization of ascorbate oxidase into the biocompatible sandwich-type composite film. Appl Biochem Biotechnol 167: 2023-2038.

56. W Shi, C Liu, Y Song, N Lin, S Zhou, et al. (2012) An ascorbic acid amperometric sensor using over-oxidized polypyrrole and palladium nanoparticles composites. Biosensors and Bioelectronics 38: 100-106.

57. JH He, ZQ Gao, ZR Song, JH He, ZQ Gao, et al. (2013) Determination of ascorbic acid based on a platinum nanoparticles modified AU electrode. Key Eng Mat 813: 562-565.

58. J Ping, Y Wang, J Wu, Y Ying, F Ji (2012) Determination of ascorbic acid levels in food samples by using an ionic liquid-carbon nanotube composite electrode. Food Chemistry 135: 362-367.

59. A Pourahmad (2012) Cell cycle arrest and induction of apoptosis by cajanin stilbene acid from Cajanus cajan in breast cancer cells. Nano Lett 7: 511 .

60. S Kumar, V Vicente-Beckett (2012) Glassy carbon electrodes modified with multiwalled carbon nanotubes for the determination of ascorbic acid by square-wave voltammetry. Beilstein J Nanotechnol 3: 388-396.

61. X Zuo, N Li, H Zhang (2012) Direct electrochemical determination of ascorbic acid by a cobalt (II) tetra-neopentyloxy phthalocyanine-multi-walled carbon nanotubes glassy carbon electrode. Journal of Materials Science 47: 2731-2735.

62. TH Tsaia, TW Chena, SM Chena, R Sarawathi (2012) Nickel, copper and manganese hexacyanoferrate with poly(3,4-ethylenedioxythiophene) hybrid film modified electrode for selectively determination of ascorbic acid. Russian Journal of Electrochemistry 48: 291-301.

63. Z Zhang, X Li, C Wang, C Zhang, P Liu, et al. (2012) A novel dinuclear Schiff-base copper (II) complex modified electrode for ascorbic acid catalytic oxidation and determination. Dalton Trans 41: 1252-1258.

64. X Zhang, G Lai, A Yu, H Zhang (2013) A glassy carbon electrode modified with a polyaniline doped with silicotungstic acid and carbon nanotubes for the sensitive amperometric determination of ascorbic acid. Microchimica Acta 180: 437-443.

65. Y Zhao, C Li, W Zhao, Q Du, B Chi, et al. (2013) Electrocatalytic oxidation of ascorbic acid on a lithium-doped tantalum oxide film coated electrode. Electrochimica Acta 107: 52-58.

66. Y Kong, X Shan, J Ma, M Chen, Z Chen (2014) A novel voltammetric sensor for ascorbic acid based on molecularly imprinted poly (o-phenylenediamine-co-o-aminophenol). Analytica Chimica Acta 809: 54-60.

67. Y Wang, Y Rui, F Li, M Li (2014) Electrodeposition of nickel hexacyanoferrate/layered double hydroxide hybrid film on the gold electrode and its application in the electroanalysis of ascorbic acid. Electrochimica Acta 117: 398-404.

68. A Zloczewska, A Celebanska, K Szot, D Tomaszewska, M Opallo, et al. (2014) Self-powered biosensor for ascorbic acid with a Prussian blue electrochromic display. Biosensors and Bioelectronics 54: 455-461.

69. H Li, M Li, W Guo, H Di, C Fang, et al. (2014) Electrochemical application of titanium dioxide nanoparticle/gold nanoparticle/multiwalled carbon nanotube nanocomposites for nonenzymatic detection of ascorbic acid. J Solid State Electrochem 18: 477-485.

70. X Liu, X Li, Y Xiong, QM Huang, XY Li, et al. (2013) A glassy carbon electrode modified with the nickel (II)-bis (1, 10-phenanthroline) complex and multi-walled carbon nanotubes, and its use as a sensor for ascorbic acid. Microchimica Acta 180: 1309-1316.

71. D Kul, ME Ghica, R Pauliukaite, MA Brett (2013) A novel amperometric sensor for ascorbic acid based on poly (Nile blue A) and functionalised multi-walled carbon nanotube modified electrodes. Talanta 111: 76-84.

72. R Zhang, S Liu, L Wang, G Yang (2013) Electroanalysis of ascorbic acid using poly (bromocresol purple) film modified glassy carbon electrode. Measurement 46: 1089-1093. 